\title{
Chronic Lymphoblastic Lymphoma
}

National Cancer Institute

\section{Source}

National Cancer Institute. Chronic Lymphoblastic Lymphoma. NCI Thesaurus. Code C8502.

This is an invalid term; lymphoblastic lymphomas are not chronic processes, but counterparts of acute lymphoblastic leukemias. 